\title{
Menopause and Role of Antioxidants, Calcium and Exercises
}

\author{
${ }^{1}$ Satwant Kaur, ${ }^{2}$ Swaran Kaur, ${ }^{3}$ Niti Mittal \\ ${ }^{1}$ Associate Professor, Department of Obstetrics \& Gyneacology M M Medical college Kumarhatti- Solan \\ HP India \\ ${ }^{2}$ Professor. Department of Pathology BPS Medical College Khanpur-Sonipat Haryana IndiaRakesh \\ Mittal assistant Professor Department of Pharmacology, Pt BD Sharma Post Graduate Institute of Medical \\ Sciences, Rohtak, Haryana, India \\ ${ }^{3}$ Demonstrator Department of Pharmacology, Pt BD Sharma Post Graduate Institute of Medical Sciences, \\ Rohtak, Haryana, India
}

\begin{abstract}
:
Objective: To study the role of antioxidants, calcium and exercises in menopausal women.

Method: In this pilot study fifty postmenopausal women were selected and they supplemented with antioxidents, calcium and adviced weight bearing exercises for three months. Thier menopausal symptoms,lipid profiles and BMD were assessed.
\end{abstract}

Results: Antioxidants, calcium and exercises reduced stress, elevate mood and enhance energy. Exercise and calcium supplementation have synergestic effect on bone denisty

Conclusion: Adequate supplementation of antioxidants, calcium along with exercises there is improvement in lipid profile, alleviation of menopausal symptoms and impruvment in bone health.

Key words: Menopausal symptoms, BMD, Antioxidants

\section{Introduction}

Menopause is defined as the permanent cessation of menstruation due to loss of ovarian follicular activity and hence lack of ovarian hormones. Menopausal women are also referred to as 'mature women`.The age at which natural menopause occurs is between the age of forty five and fifty five with a mean at around fifty one years for women worldwide. Menopause is the time in a woman's life when reproductive capacity ceases. The ovaries stop functioning and thier production of steriod hormones fall. A variety of physiological changes take place in the body at this time. Some of these changes are results of cessation of ovarian functions with resulting deficiency of hormones. Superadded to this are other concurrent changes that are a result of the ongoing ageing process combined with concommitent life changes. About $73 \%$ of women report troublesome symptoms during menopause. The most common symptoms are hot flushes and vaginal atrphy. Other symptoms are irritability, depression, night sweats, palpition, mood swings, aging of skin, osteoporosis, decreased immune function and weaking of muscles. Long term systemic effects of menopause are cardiovascular problems,joint problems, connective tissue \& collagen disorders and neurogical problems. Antioxidants are substances that protect against the deleterious effects of free radicals arising as a by product of normal metabolism or by chemical accidents. These are vitamins like A,C,E, carotenoids cystine glutathione. Minerals like selenium, zinc, copper, iron, chromium, manganese. Under normal circumstances in healthy individuals the effect of oxidants is counteracted by antioxidant defenses found in body's cell compartments in the form of enzymatic and non- enzymatic antioxidants. Menopausal women are vulnerable to the action of free radicals because of loss of the antioxidant effect of estrogen as well as the decreased competence of antioxidants defenses with ageing. Hence there is need of antioxidants, which is sufficient to prevent deficiency and to reduce the enhanced oxidative stress and decrease the risk of diseases associated with ageing. Calcium influences bone strength through its effect on bone mass. Calcium intake is one of the important modifiable envirronmental factors for the normal development of the skeleton during growth and the maintenance of bone mass in later life. After menopause, women lose bone at a rate of 2-3\% per year. This is mostly due to the deficiency of estrogen at menopause which leads to decreased intestinal calcium absorption and renal calcium re- absorption $(1,2,3,4)$. So there is need of intake of $1200-1500 \mathrm{mg} / \mathrm{day}$ of calcium in menopausal women. Calcium supplementation and exercise have synergistic effect on bone denisty. Apart from this, exercise can improve self-esteem, reduce stress, elevate mood, enhance energy, reduces chances of cardiovascular disease, increase muscle mass and body metabolism thus resulting in weight loss and alteration of the muscle-fat ratio. Hence regular exercise prescription for menopausal women is an 
adjunct therapy to enhance the medication's effect on bones and the cardiovascular system. weight bearing exercises, are those in which the bones and muscles work against gravity like walking, dancing, jogging and stair climbing. These can help menpausal women stay healthier.

\section{Methods And Materials}

This randomized trial was performed to determine and compare the effect of antioxidants, calcium and exercise with that of placebo in reducing the menopausal symptoms, improvement in lipid profile and improvement in bone mass. Total fifty postmenopausal women with the age of 45-60 years (mean age 51 years) were selected. The study was approved by Ethical Committee of Adesh Medical college Bathinda, where study was performed. Wrritten informed consent was obtained from all women. Women with both natural and surgical menopause were included. Exclusion criteria were women on HRT therapy and hypersensitivity to study drugs. Women were randomized and divided into two groups where group $\mathrm{A}(25)$ received antioxidend, cal cium and exercise plan while group B (25) received placebo treatment.

Primary efficacy endpoints were improvement in the symptoms including; hot flushes, night sweats tiredness, insomnia and feeling of well being. The secondry endpoints were improvement in lipid profile, hemoglobin, reduction in weight and improvment in bone mineral denisty i.e BMD.

Group A received one antioxident capsule,calcium $(1200 \mathrm{mg})$ and a plan of weight -bearing and strenght-training exercise for three months. The improvment in symptoms were graded as minimal, good and almost complete on 30th, 60th and 90th day(Table 1). Lipid profile, hemglobin, weight and BMD were also evaluated on the same days(Table2).

\section{Results} considered

Results were analyzed statistically by the Chi- Square test. P value less than 0.05 was At baseline 25 women each from group A \& B reported menopausal symptoms. On the 90th day, 15 women(60\%) in group A as compared to $4(16 \%)$ in group B reported almost complete improvement $(\mathrm{p}=0.001) .8(32 \%)$ women in group A reported moderate improvement as compared to $13(52 \%)$ in groupB. Only $2(8 \%)$ women in group A reported minimal improvement as compared to $8(32 \%)$ in group B. (Table 1) The secondary endpoints were also show improvement. There was increase in BMD by $5-10 \%$ in group A as compared to group B. Similarly group A show improved results in lipid profile i.e reduces LDL, increasesHDL and reduced levels of triglycerides. There were also increase of hemoglobin by $20 \%$ in group A as compared to group B.(Table 2)

Table 1 - Improvment in symptos

\begin{tabular}{|l|l|l|}
\hline Improvement in symptoms & Group A ( 25 ) & Group B ( 25 ) \\
\hline & Post Treatment -90th days & Post Treatment -90th days \\
\hline & & \\
\hline Complete & $15=60 \%$ & $4=16 \%$ \\
\hline & & \\
\hline Modrate & $8=32 \%$ & $13=52 \%$ \\
\hline & & \\
\hline Minimal & $8=8 \%$ & $8=32 \%$ \\
\hline
\end{tabular}

Table 2- secondary endpoints

\begin{tabular}{|c|c|c|}
\hline Parameters & Group A $=25$ & Group A $=25$ \\
\hline BMD & & \\
\hline & Increase in $10 \%$ & Nil \\
\hline Lipid profile & & \\
\hline & Improved in 30\% & Improved in 3\% \\
\hline $\mathrm{Hb} \%$ & Increase in 20\% & NIL \\
\hline & & \\
\hline Reduction in wt & $\operatorname{In} 40 \%$ & $\operatorname{In} 6 \%$ \\
\hline
\end{tabular}

\section{Discussion}

In our study key symptoms of menopause were quantified to assess the effectiveness of antioxidants, calcium and exercise in menopause. Antioxidants supplements significantly reduces the postmenopausal symptoms and improved general well being suggesting their important role in the treatment of menopausal symptoms. Antioxidants like vitamin $\mathrm{C}$ improve the endothelial function in postmenopausal women with established estrogen deficiency (5). Evidence indicates that postmenopausal women have increased plasma homocysteine level. Folic acid, vitamin B6 and vitamin B12 is associated 
with a significant reduction in plasma concentrations of homocysteine( $6,7,8,9)$. Postmenopausal osteoprosis is characterized by low bone mass and microarchitectural deterioration of bone tissue leading to enhanced bone fragility and increased fracture risk $(10,11,12,13)$. India seems to have a very high prevalence of osteoporosis, which may be due to associated nutritional vitamin $\mathrm{D}$ and calcium deficiency $(14,15,16)$. Osteoporosis is a preventable disease. Prevention starts from childhood and the goals include regular weight- bearing exercise, good general nutrition, adequate intake of calcium and vitaminD and not smoking(17). All perimenopausal and postmenopausal women should undergo a bone denisty scan to establish thier baseline status. All peri \& postmenopausal women should receive both calcium and vitamin D supplements, including 1000-1200mg calcium and 800iu vitamin D daily(18). Exercise and calcium supplementation have synergistic effect on bone denisty. Exercise can improve self esteem, reduces stress, elevate mood and enhance energy. Regular exercise reduces risks associated with reduced estrogen i.e reduces LDL, increasesHDL, chlesterol and reduces the levels of blood triglycerides and fibrinogen and increases cardiorespiratory endurance(19). PFMT(pelvic floor muscle training) also known as Keigel's exercises, are very much effective treatment among various other treatment modalities for a very common kind of bladder problem i.e stress and urge incontinence. There are three types of exercise that can help postmenopausal women stay healthier; aerobic, weight bearing and flexibility exercises help reduce the depression and irritability that can come with menopause.

\section{Conclusion}

A nonhormonal nutritional supplement i.e antioxident and calcium along with regular exercise schedule provides relief and prevention from menopausal symptoms. Results obtained from this study supports to the evidence that long-term treatment with antioxident, calcium supplement along with exercise could be more effective in improving symptoms related to menopause without any detrimental effects on womem's health. The regime also appears to be a safe and effective alternative to HRT for postmenopausal women. The potential to increase bone mass, and to compensate for bone loss due to osteoporosis, is a benefit of calcium intake and exercise that should not be overlooked.

\section{References}

[1]. Prince RL, Counterpoint: estrogen effects on calcitropic hormones and calcium homeostasis. Endocr Rev 1994;15:301-9.

[2]. Prince R, Devine A, Dick I Criddle A, Kerr D, Kent N,et al. The effects of calcium sopplementation (milk powder or tablets) and exercise on bone density in postmenopausal women. J BONE Miner Res 1995;10:835-42.

[3]. Shea B, Wells G, Cranney A, Zytaruk N, Robinson V, Griffith L, et al. Meta-analyses of therapies for postmenopausal osteoporosis. VII. Meta-analysis of calcium supplementation for the prevention of postmenopausal osteoporosis. Endocr Rev 2002; 23:552-9.

[4]. Prince RL, DevineA, Dhaliwal SS, Dick IM. Effects of calcium supplementation on clinical fracture and bone structure: results of a 5-year, double- blind, placebo-controlled trial in elderly women. Arch Intern Med 2006;166:869-75

[5]. McSorley PT, Young IS, Bell PM, Fee JP, McCance DR. Vitamin C improves endothelial function in healthy estrogen-deficient postmenopausal women. Climacteric.2003;6(3):238-47.

[6]. Villa P, Perri C, Suriano R, Cucinelli F, Panunzi S, Ranieri M. L-folic acid supplementation in healthy postmenopausal women: effect on homocysteine and glycolipid metabolism. J Clin Endocrino Metab.2005;90(8):4622-29.

[7]. De Leo V, La Marca A, Morgante G et al. Low-dose folic acid supplementation reduces plasma levels of the cardiovascular risk factor homocystine in postmenopausal women. Am J Obstet Gynecol.2000;183(4):945-47.

[8]. Smolders RG, de Meer K, Kenemans P, Teerink T et al. Hormone replacement influences homocystine levels in the methionineloading test: a randomized placebo contrlled trial in postmenopausal women. Eur J Obstet Gynecol Report Bio.2004;117(1):55-59.

[9]. Moustapha A, Robinson K Homocystine: an emerging age-related cardiovascular risk factor. Geriatrics 1999;54(4):41,44-46,49-51.

[10]. American Association of Clinical Endocrinologists2001 Medical Guidelines for clinical practice for the prevention and management of postmenopausal osteoporosis. Endocrine Practice.2001;7(No.4):293-312.

[11]. Osteoporosis: review of the evidence for prevention, diagnosis and treatment and cost-effectiveness analysis[executive summary]. Osteoporosis Int.1998;8(suppl 4):S3-S6.

[12]. Kiel DP, Felson DT, Anderson JJ, Wilson PW, Moskowitz MA. Hip fracture and the use of estrogen in postmenopausal women: the Framingham study. N Engl J Med1987;317:1169-1174.

[13]. WHO. Who are the candidates for prevention and treatment for Osteoporosis?Osteoporosis Int 1997;7:1-6.

[14]. Gupta A. Osteoporosis in India-the nutritional hypothysis. In:Metabolic Bone Disorders. Indian Society for Bone and Mineral Research, Ed: Mithal A, Rao ds, Zaidi M. 1998;115-132.

[15]. Goswami R, Gupta N Goswami D, Marwaha RK, Tondon N, Kochupillai N. Prevelence and significance of low 25(OH)D concentration in healthy subjects in Delhi. Am J Clin Nutr 2000:72:472-5.

[16]. Mithal A, Arya V, Vitamin D status in urban North Indians adults J Bone Miner Res, 14,1999(suppl). Abstract.

[17]. Interim Report and Recomdations of the World Health Organization Task-Force for Osteoporosis. Osteoporosis Int 1999;10:259264.

[18]. Rizzoli R, Boonen S,Brandi ML, Burlet N, Delmas P, Reginster JY. The role of calcium vitamine D in the management of osteoporosis. Bone2008;42:246-9.

[19]. Schaberg- Lorei, G, et al. Body composition alterations consequent to an exercise program for pre and postmenopausal women. Journal of Sposts Medicine and Physical Fitness, 1990;30(4):426-33. 